\title{
Editorial
}

\section{Sleep and Neurodevelopmental Disorders}

\author{
Oskar G. Jenni ${ }^{1}$ \\ ${ }^{1}$ Child Development Center, University Children's Hospital Zurich, \\ Zurich, Switzerland
}

Neuropediatrics 2015;46:157-158.

Sleep disorders in children are among the most common parental complaints to health care professionals and frequently occur in children with neurological and developmental disorders. Thus, I am grateful to the editors of Neuropediatrics for the opportunity to assemble in one place several papers that outline the contemporary knowledge about sleep disorders in patients with neurodevelopmental disabilities. Major advances in children's sleep research and pediatric sleep disorders medicine have occurred in recent years, and it is perfect timing to bring together perspectives of such a distinguished group of clinicians and scientists.

In this issue, Mouthon and Huber ${ }^{1}$ describe recent developments in the methodology to assess sleep and its disorders in children. While sleep questionnaires, actigraphy, and polysomnography are established techniques in pediatric sleep research and medicine since many decades, latest scientific advances in electroencephalography (EEG) and EEG signal analysis have provided new opportunities in understanding the regulation of children's sleep and its disorders and have offered an undisturbed window into the developing brain. For instance, the topography of EEG sleep slow wave activity-a marker of sleep regulatory mechanisms, sleep homeostasis, and synaptic processeswas shown to parallel cortical maturation during development. $^{2,3}$

Advanced EEG analyses have also led to new insights into the mechanisms of specific epilepsy syndromes as outlined in the review article by Schmitt ${ }^{4}$ in this special issue. His review describes in detail the close and reciprocal association between sleep and seizure disorders. In fact, more than half of all seizure episodes occur at night and patients with epilepsy frequently suffer from poor sleep and tiredness. Recent studies have shown that altered slow wave sleep in young patients with seizures may cause the sleep problems and also contribute to the underlying mechanisms of the developmental regression of these children. ${ }^{5,6}$

Over the past years, the awareness that narcolepsy is as disorder which also occurs during childhood has been increased. In fact, more and more colleagues see growing numbers of young patients with narcolepsy and, thus, comprehensive and up-to-date knowledge about this devastating disorder during childhood is strongly needed. Rocca and co-authors ${ }^{7}$ have contributed to this special issue with the latest update on childhood narcolepsy. I do believe that this overview from one of the leading European centers will improve the clinical care of these patients.

Finally, Angriman and colleagues ${ }^{8}$ summarize the diverse sleep problems that often occur in children with developmental disabilities such as Angelman, Rett, Fragile$\mathrm{X}$ syndromes, and others. They present clinical and therapeutic approaches to help these children and their families. An important role in the management of these patients lies in the pharmacological treatment. However, behavioral approaches in these children are as important as medication. Our group has recently presented a well-structured intervention concept (the Zurich 3-step concept ${ }^{9}$ ) which focuses on basic physiological models of sleep regulation (i.e., introducing a regular rhythm and adjusting bedtime to sleep need), and uses behavioral strategies to handle elements of maladaptive learned sleep behavior, in both healthy children and those with neurological and developmental disorders.

I understand that this special issue of Neuropediatrics is focusing on selected disorders of neurologically impaired children. However, I also believe that, as the 21st century continues to unfold, there is a great need for understanding the general role of sleep as a foundation for the children's development across many different domains. Thus, I eagerly await the further developments in this area of sleep research over the next years.

\section{References}

1 Mouthon AL, Huber R. Methods in pediatric sleep research and sleep medicine. Neuropediatrics 2015;46(3):159-170

2 Buchmann A, Ringli M, Kurth S, et al. EEG sleep slow-wave activity as a mirror of cortical maturation. Cereb Cortex 2011;21(3): $607-615$
C 2015 Georg Thieme Verlag KG Stuttgart · New York
DOI http://dx.doi.org/ 10.1055/s-0035-1551941. ISSN 0174-304X.
Address for correspondence
Oskar G. Jenni, MD, Child

Development Center, University

Children's Hospital Zurich,

Steinwiesstrasse 75, CH-8032

Zurich, Switzerland

(e-mail: Oskar.Jenni@kispi.uzh.ch).
Issue Theme Sleep and Neurodevelopmental Disorders; Guest Editor, Oskar G. Jenni, MD 
3 Kurth S, Ringli M, Geiger A, LeBourgeois M, Jenni OG, Huber R. Mapping of cortical activity in the first two decades of life: a high-density sleep electroencephalogram study. J Neurosci 2010; 30(40):13211-13219

4 Schmitt B. Sleep and epilepsy syndromes. Neuropediatrics 2015; 46(3):171-180

5 Bölsterli BK, Schmitt B, Bast T, et al. Impaired slow wave sleep downscaling in encephalopathy with status epilepticus during sleep (ESES). Clin Neurophysiol 2011;122(9): 1779-1787

6 Fattinger S, Schmitt B, Bölsterli Heinzle BK, Critelli H, Jenni OG, Huber R. Impaired slow wave sleep downscaling in patients with infantile spasms. Eur J Paediatr Neurol 2015;19(2): 134-142

7 Rocca FL, Pizza F, Ricci E, Plazzi G. Narcolepsy during childhood: an update. Neuropediatrics 2015;46(3):181-198

8 Angriman M, Caravale B, Novelli L, Ferri R, Bruni O. Sleep in children with neurodevelopmental disabilities. Neuropediatrics 2015;46(3):199-210

9 Werner H, Hunkeler P, Benz C, et al. The Zurich 3-step concept for the management of behavioral sleep disorders in children: A before-and-after study. J Clin Sleep Med 2015;11(3): 241-249 